OPEN ACCESS

Edited by:

Galila Agam,

Ben-Gurion University of the Negev,

Israel

Reviewed by:

Tullio Florio,

Università di Genova, Italy

Federico Herrera,

Instituto de Tecnologia Química e

Biológica (ITQB-NOVA), Portugal

${ }^{*}$ Correspondence:

Tim Vervliet

tim.vervliet@kuleuven.be

Received: 22 January 2018 Accepted: 13 March 2018

Published: 27 March 2018

Citation:

Vervliet T (2018) Ryanodine Receptors in Autophagy: Implications for Neurodegenerative Diseases?

Front. Cell. Neurosci. 12:89. doi: 10.3389/fncel.2018.00089

\section{Ryanodine Receptors in Autophagy: Implications for Neurodegenerative Diseases?}

\author{
Tim Vervliet*
}

Laboratory of Molecular and Cellular Signaling, Department of Cellular and Molecular Medicine, KU Leuven, Leuven, Belgium

Intracellular $\mathrm{Ca}^{2+}$ signaling is important in the regulation of several cellular processes including autophagy. The endoplasmic reticulum (ER) is the main and largest intracellular $\mathrm{Ca}^{2+}$ store. At the ER two protein families of $\mathrm{Ca}^{2+}$ release channels, inositol 1,4,5trisphosphate receptors ( $\left(\mathrm{P}_{3} \mathrm{Rs}\right)$ and ryanodine receptors (RyRs), are expressed. Several studies have reported roles in the regulation of autophagy for the ubiquitously expressed $I P_{3} R$. For instance, $I_{3} R$-mediated $\mathrm{Ca}^{2+}$ release supresses basal autophagic flux by promoting mitochondrial metabolism, while also promoting the rapid initial increase in autophagic flux in response to nutrient starvation. Insights into the contribution of RyRs in autophagy have been lagging significantly compared to the advances made for $I P_{3} R s$. This is rather surprising considering that RyRs are predominantly expressed in long-lived cells with specialized metabolic needs, such as neurons and muscle cells, in which autophagy plays important roles. In this review article, recent studies revealing roles for RyRs in the regulation of autophagy will be discussed. Several RyR-interacting proteins that have been established to modulate both RyR function and autophagy will also be highlighted. Finally, the involvement of RyRs in neurodegenerative diseases will be addressed. Inhibition of RyR channels has not only been shown to be beneficial for treating several of these diseases but also regulates autophagy.

Keywords: ryanodine receptor, autophagy, $\mathrm{Ca}^{2+}$ signaling, neurodegenerative diseases

\section{INTRODUCTION}

Intracellular $\mathrm{Ca}^{2+}$ signaling regulates a wide array of cellular processes such as cell division, muscle contraction, memory formation, secretion, cell death, autophagy... (Berridge, 2001). Although many different organelles are involved in $\mathrm{Ca}^{2+}$ signaling, the endoplasmic reticulum (ER) functions as the main intracellular $\mathrm{Ca}^{2+}$ store. Within the lumen of the ER maintaining adequate $\mathrm{Ca}^{2+}$ levels is essential to promote the correct folding of proteins. Failure to do so results in ER stress and activation of the unfolded protein response (Mekahli et al., 2011; Carreras-Sureda et al., 2018). In response to extracellular stimuli and agonists such as growth factors, hormones, neurotransmitters and antibodies, $\mathrm{Ca}^{2+}$ release from the ER is a common extensively regulated event (Berridge, 2001). $\mathrm{Ca}^{2+}$ responses can occur in highly localized microdomains, enabling intimate $\mathrm{Ca}^{2+}$ signaling between different organelles like the ER and mitochondria and the ER and lysosomes (Laude and Simpson, 2009; Kilpatrick et al., 2017; Pedriali et al., 2017) or they can spread across the entire cell as $\mathrm{Ca}^{2+}$ oscillations and waves (Thul et al., 2008). Depending on the spatio-temporal profile of the $\mathrm{Ca}^{2+}$ response, different processes are affected (Berridge et al., 2003). Long lasting $\mathrm{Ca}^{2+}$ oscillations, for instance are known to promote cell survival by stimulating mitochondrial ATP production, whereas excessive $\mathrm{Ca}^{2+}$ release is associated with cell death. 
The cellular components involved in $\mathrm{ER} \mathrm{Ca}^{2+}$ dynamics have been studied extensively and are well-characterized in terms of function and regulation. $\mathrm{Ca}^{2+}$ is actively transported into the ER via the sarco/endoplasmic reticulum $\mathrm{Ca}^{2+}$ ATPase (SERCA; Vandecaetsbeek et al., 2011). The majority of $\mathrm{Ca}^{2+}$ release from the ER is mediated by two families of $\mathrm{Ca}^{2+}$. permeable channels, inositol 1,4,5-trisphosphate $\left(\mathrm{IP}_{3}\right)$ receptors (IP ${ }_{3}$ Rs; Foskett et al., 2007; Parys and De Smedt, 2012; Ivanova et al., 2014; Mikoshiba, 2015) and ryanodine receptors (RyRs; discussed in more detail later in this review article). $\mathrm{IP}_{3} \mathrm{R}$ are a class of tetrameric intracellular $\mathrm{Ca}^{2+}$-release channels gated by the second messenger $\mathrm{IP}_{3}$ (Parys and De Smedt, 2012). $\mathrm{IP}_{3} \mathrm{R}-$ mediated $\mathrm{Ca}^{2+}$ signaling is present in virtually all cells and is involved in the regulation of mitochondrial bioenergetics, autophagy, cell death... (Cárdenas et al., 2010, 2016; Bultynck, 2016). Besides $I_{3}$ Rs and RyRs, other proteins involved in ER $\mathrm{Ca}^{2+}$ release or leak pathways are Bax Inhibitor-1, pannexin-1, translocon, presenilins and Orai2 (Sammels et al., 2010b). Apart from the ER, the mitochondria, lysosomes and the golgi apparatus are known to sequester $\mathrm{Ca}^{2+}$ and contribute to $\mathrm{Ca}^{2+}$ signaling events (Raffaello et al., 2016). ER, mitochondria and lysosomes are also important organelles in the regulation of autophagy (La Rovere et al., 2016). It is therefore not surprising that $\mathrm{Ca}^{2+}$ signaling is involved in the regulation of autophagy (Decuypere et al., 2011a).

\section{$\mathrm{Ca}^{2+}$ SIGNALING IN AUTOPHAGY}

Autophagy is a degradation pathway responsible for maintaining proper cell homeostasis. It removes damaged organelles or helps cells cope with stress situations such as starvation, the accumulation of unfolded proteins or infections. Three forms of autophagy, micro-, macro- and chaperone-mediated autophagy, are known to exist which all end with degradation in the lysosomes (Decuypere et al., 2011a). Macroautophagy (from here on referred to as autophagy) is a complex signaling pathway involving several steps which guide the formation, elongation, maturation and finally fusion of phagophores with lysosomes. Several of these steps are $\mathrm{Ca}^{2+}$ dependent (Decuypere et al., 2011a). Both stimulatory and inhibitory effects of $\mathrm{Ca}^{2+}$ on autophagy have been described, which likely reflects a strict spatio-temporal control of autophagy by $\mathrm{Ca}^{2+}$ signaling, recently discussed in great detail in Bootman et al. (2018). In Brief, $\mathrm{Ca}^{2+}$ influx through voltage-gated $\mathrm{Ca}^{2+}$ channels has been shown to inhibit autophagy by activating calpains that cleave ATG5, which is important for autophagosome elongation (Williams et al., 2008; Xia et al., 2010). As for stimulatory effects, several studies have shown that increased cytosolic $\mathrm{Ca}^{2+}$ levels trigger the activation of calmodulin, thus activating the AMP-activated protein kinase (AMPK) via calmodulin kinase kinase $\beta$ leading to the inhibition of the mechanistic target of rapamycin (mTOR), thereby inducing autophagy (Høyer-Hansen et al., 2007; Law et al., 2010).

At the level of the ER, the $\mathrm{IP}_{3} \mathrm{R}$ was shown to be involved in the regulation of autophagy. A continuous $\mathrm{Ca}^{2+}$ transfer from the ER to the mitochondria is necessary to maintain proper ATP production thereby inhibiting the activation of AMPK and thus inhibiting autophagy (Cárdenas et al., 2010). In particular, cancer cells appear to depend critically on these constitutive ER-mitochondrial $\mathrm{Ca}^{2+}$ fluxes for their survival, since genetic or pharmacological interference with such fluxes results in cancer cell death (Bultynck, 2016; Cárdenas et al., 2016). For a more in-depth review on the regulation of autophagy by $\mathrm{IP}_{3} \mathrm{Rs}$, I would like to refer to the following reviews (Parys et al., 2012; Kania et al., 2017).

\section{THE RYANODINE RECEPTOR (RyR)}

RyRs are large ( $>500 \mathrm{kDa}$ ) ER-located $\mathrm{Ca}^{2+}$-permeable channels of which three isoforms are known to exist. These channels form and function as tetramers (Lanner et al., 2010). In contrast to the ubiquitously expressed $\mathrm{IP}_{3}$ Rs, RyRs have a distinct expression pattern restricted to specific cell types such as T-cells and excitable cells. Tissues expressing RyRs include heart, skeletal and smooth muscle, brain, pancreas and the liver. From these tissues, skeletal muscles, heart and neurons have the highest RyR-expression levels (Lanner et al., 2010). More specifically, skeletal muscle cells express large amounts of RyR1 (Lai and Meissner, 1989), heart cells express RyR2 (Imagawa et al., 1989) whereas all three RyR isoforms are expressed in different areas of the brain (Martin et al., 1998). Given this rather restricted expression pattern, it is not surprising that RyRs are involved in several tissue-specific processes. In muscle and heart cells, RyR1 and RyR2 are critically involved in excitationcontraction coupling. In neurons long term potentiation and long term depression are known to be at least in part RyR dependent (Lanner et al., 2010). In the pancreas, RyRs are involved in the secretion of insulin (Santulli et al., 2015) and they also contribute to the development of bile acid-induced acute pancreatitis (Husain et al., 2012). Physiological RyR activators are $\mathrm{Ca}^{2+}$, cyclic-ADP ribose and NAADP (Meissner et al., 1997; Kunerth et al., 2004; Gerasimenko et al., 2006). However, it remains unclear whether NAADP activates RyRs directly or via $\mathrm{Ca}^{2+}$-induced $\mathrm{Ca}^{2+}$ release (CICR) initiated at the level of the lysosomes via NAADP-sensitive $\mathrm{Ca}^{2+}$ channels. Pharmacologically RyRs can be activated by caffeine or low ryanodine concentrations ( $\mathrm{nM}$ range), locking the channel in a sub-conductance state. Inhibition of RyRs can be obtained most specifically via a high ryanodine conentrations $(>20 \mu \mathrm{M})$ or with dantrolene, a FDA-approved RyR blocker.

\section{REGULATION OF THE RyR BY PROTEIN-PROTEIN INTERACTIONS}

RyR channels are regulated by many different cellular components $\left(\mathrm{Ca}^{2+}, \mathrm{Mg}^{2+}\right.$ and ATP), post translational modifications and protein interactions (Lanner et al., 2010). In this section, we will focus on a number of proteins that regulate RyR-mediated $\mathrm{Ca}^{2+}$ release, which may potentially impact its role in autophagy.

\section{B-Cell Lymphoma (Bcl)-2 and Bcl- $\mathrm{X}_{\mathrm{L}}$}

The Bcl-2-protein family is well known as critical regulator of apoptosis. This family consists of anti- and pro-apoptotic 
members, which are all characterized by the presence of at least one and maximum four Bcl-2 homology $(\mathrm{BH})$ domains (Letai, 2008). Anti-apoptotic Bcl-2 and Bcl- $\mathrm{X}_{\mathrm{L}}$ bind to pro-apoptotic family members thereby preventing apoptosis-induction at the mitochondria (Brunelle and Letai, 2009). In addition to the regulation of apoptosis at the level of the mitochondria, Bcl-2 proteins have emerged as critical modulators of intracellular $\mathrm{Ca}^{2+}$-transport systems and $\mathrm{Ca}^{2+}$ signaling events (Vervliet et al., 2016). Both Bcl-2 and Bcl- $\mathrm{X}_{\mathrm{L}}$ have been extensively shown to regulate $\mathrm{IP}_{3} \mathrm{R}$-mediated $\mathrm{Ca}^{2+}$ release in several manners (Chen et al., 2004; White et al., 2005; Hanson et al., 2008; Rong et al., 2009; Eckenrode et al., 2010; Monaco et al., 2012; Yang et al., 2016). Other $\mathrm{Ca}^{2+}$-signaling related targets of anti-apoptotic Bcl-2 proteins include the plasma membrane $\mathrm{Ca}^{2+}$ ATPase (Ferdek et al., 2012), SERCA (Dremina et al., 2004) and the voltage dependent anion channel (VDAC; Shimizu et al., 1999).

Recently, we have shown that both Bcl-2 and Bcl- $\mathrm{X}_{\mathrm{L}}$ bind to and inhibit RyRs (Vervliet et al., 2014, 2015a). Both proteins bound to a centrally located region on the RyR, showing a striking similarity to the Bcl-2 binding site in the central domain of the $\mathrm{IP}_{3} \mathrm{R}$ (Rong et al., 2009). The fourth $\mathrm{BH}$ (BH4) domain of $\mathrm{Bcl}-2$ and $\mathrm{Bcl}-\mathrm{X}_{\mathrm{L}}$ was sufficient for inhibiting RyR-mediated $\mathrm{Ca}^{2+}$ release. However, in full-size Bcl$\mathrm{X}_{\mathrm{L}}$, also the $\mathrm{BH} 3$ domain and more specifically lysine 87 , within this domain, was important for targeting and inhibiting RyR activity.

\section{Presenilins}

Presenilins form the catalytic subunit of $\gamma$-proteases. Substrates of presenilins include notch and the amyloid precursor protein (De Strooper et al., 2012). Presenilins are extensively studied for their role in the development of Alzheimer's disease (AD; Selkoe and Hardy, 2016). In AD, presenilin mutations alter the cleavage of the amyloid precursor protein, enhancing the formation of pathological amyloid beta. This pathological amyloid beta aggregates and forms plaques that are considered as an important hallmark of the disease. Besides their actions as proteases, presenilins are also known to play roles in $\mathrm{Ca}^{2+}$ signaling. At the ER, presenilins have been implicated in inducing a passive ER $\mathrm{Ca}^{2+}$ leak. It was proposed that these proteins can form $\mathrm{Ca}^{2+}$-permeable pores potentially functioning as a $\mathrm{Ca}^{2+}$-leak channel (Nelson et al., 2007). This unconventional role for presenilins as $\mathrm{Ca}^{2+}$-leak channels also surfaced in an unbiased systems biology approach using a collection of siRNAs against $\mathrm{Ca}^{2+}$ regulators in living single cells (Bandara et al., 2013). Presenilins also regulate $\mathrm{IP}_{3} \mathrm{R}$ channel function and expression, which may contribute to their $\mathrm{ER} \mathrm{Ca}^{2+}$ leak properties (Kasri et al., 2006; Cheung et al., 2010; Wu et al., 2013).

RyR expression and function is also dependent on presenilins. Loss of presenilins in primary hippocampal neurons resulted in a decrease in RyR expression and reduced RyR-mediated $\mathrm{Ca}^{2+}$ release, impairing pre-synaptic function (Wu et al., 2013). In addition, an $\mathrm{N}$-terminal fragment of presenilin-1 was shown to inhibit RyR-mediated $\mathrm{Ca}^{2+}$ release, thereby directly regulating RyR channel activity (Payne et al., 2013).

\section{Polycystins (PC)}

Polycystin (PC) 1 and 2 are important regulators of intracellular $\mathrm{Ca}^{2+}$ signaling (Lemos and Ehrlich, 2018). Both PC1 and PC2 are present at ER membranes, plasma membranes and cilia. PC2 is a non-selective $\mathrm{Ca}^{2+}$-permeable cation channel, whereas PC1 is important for PC2 localization and functioning (Tsiokas et al., 2007; Delling et al., 2013). Loss of function of either PC results in the development of polycytic kidney disease, a disease characterized by aberrant intracellular $\mathrm{Ca}^{2+}$ signaling leading to cyst growth and ultimately kidney failure (Torres et al., 2007). These alterations in $\mathrm{Ca}^{2+}$ homeostasis are generally attributed to loss of correct $\mathrm{PC} 2$ functioning or altered regulation of different $\mathrm{Ca}^{2+}$ release channels by PC1 or PC2. The $\mathrm{IP}_{3} \mathrm{R}$ for instance is regulated by both $\mathrm{PC} 1$ and PC2. PC1 interacts with the $\mathrm{IP}_{3} \mathrm{R}$ thereby inhibiting $\mathrm{IP}_{3} \mathrm{R}$-mediated $\mathrm{Ca}^{2+}$ release whereas PC2 mediates the opposite effect on the IP ${ }_{3} \mathrm{R}$ (Li et al., 2005, 2009; Sammels et al., 2010a).

In cardiomyocytes, RyR2 is regulated by PC2 (Anyatonwu et al., 2007). It was shown that PC2 interacts with RyR2, thereby inhibiting the channel. Knock out of PC2 resulted in increased frequency of $\mathrm{Ca}^{2+}$ oscillations in the cardiomyocytes and reduced the $\mathrm{ER} \mathrm{Ca}^{2+}$ store content. Recently, it was shown that a decrease in PC2 expression increased the expression of RyR2 and SERCA2A in the heart while phosphorylated phospholamban, a SERCA inhibitor in its non-phosphorylated form, was decreased (Kuo et al., 2014). These results indicate that PC2 regulates RyRs and $\mathrm{Ca}^{2+}$ signaling in the heart at multiple levels.

\section{THE RyR IN AUTOPHAGY}

As mentioned above intracellular $\mathrm{Ca}^{2+}$ signaling is a versatile regulator of autophagy. Major advances on the regulation of autophagic flux by $\mathrm{IP}_{3} \mathrm{Rs}$ in nutrient-rich and starvation conditions but also in response to treatments with for instance rapamycin and resveratrol have been made (Kania et al., 2017). However, our understanding of how RyR-mediated $\mathrm{Ca}^{2+}$ release modulates the autophagic process has lagged compared to the progress made for $\mathrm{IP}_{3}$ Rs. A major issue for studying the role of RyRs in autophagy has been the lack of easy-to-use cell models that express RyRs endogenously. As autophagy is easily influenced by many factors, expressing exogenous RyRs in cells that do not have adequate RyR regulators, may alter autophagy and other processes in a way that may have little physiological relevance. Therefore, it is important to include model systems expressing endogenous RyRs as well, to assess whether or not the observations are replicable in a more physiological setting. That being said, high RyR expression is observed in skeletal muscle, heart and brain cells, which are all long-lived cells with specific metabolic needs where autophagy plays important roles. In addition, in these tissues RyR-mediated $\mathrm{Ca}^{2+}$ release is important for performing several main functions like muscle contraction and neuronal processes related to synaptic transmission and memory formation. As RyRs are activated by CICR (Lanner et al., 2010) they may serve to amplify $\mathrm{Ca}^{2+}$ signals or initiate local $\mathrm{Ca}^{2+}$ signals that contribute to the sensitization of $\mathrm{Ca}^{2+}$. handling systems promoting $\mathrm{ER} \mathrm{Ca}^{2+}$ release thus modulating 
autophagy in a positive or negative way (Bootman et al., 2018). Recently, a number studies have emerged, thereby revealing a role for RyR channels in autophagy regulation.

First, the involvement of RyR3 in autophagic cell death, a non-apoptotic form of programmed cell death driven by autophagy (Edinger and Thompson, 2004), was demonstrated in adult neuronal hippocampal stem cells (Chung et al., 2016). The authors showed that in these cells, insulin withdrawal increased the protein levels of LC3-II, an important autophagic flux marker (Klionsky et al., 2016), suggesting a stimulation of the autophagic flux. Insulin deprivation also upregulated RyR1 and RyR3-mRNA correlating with increased $\mathrm{Ca}^{2+}$ release from the ER, resulting in elevated cytosolic $\mathrm{Ca}^{2+}$ levels. Pharmacological inhibition of RyRs using dantrolene could counteract the increase in LC3-II levels. It is likely that RyR3 upregulation was a toxic event that contributed to the observed autophagic cell death induced by insulin withdrawal, as dantrolene could protect against this, while caffeine had the opposite effect. These findings were supported by CRISPR/Cas9-mediated knockout of RyR3 in these neuronal stem cells, indicating that the RyR3-deficient stem cells did not display the observed $\mathrm{Ca}^{2+}$ rises and were protected from autophagic cell death in response to insulin withdrawal.

The effects of propofol, a commonly used intravenous anesthetic known to induce neuronal damage and learning deficits in rat (Milanovic et al., 2010; Karen et al., 2013), on autophagy regulation have also been reported recently (Qiao et al., 2017). Treatment of cortical progenitor cells with a high dose of propofol resulted in cytotoxicity which was dependent on both $\mathrm{IP}_{3} \mathrm{R}$ and RyR activation. The authors linked this cytotoxicity to excessive autophagy activation, measured by increased LC3-II levels after propofol treatment. Inhibition of either $\mathrm{IP}_{3} \mathrm{Rs}$ or RyRs, using xestospongin $\mathrm{C}$ or dantrolene respectively, reduced LC3-II to control levels and increased cell viability. Suggesting RyRs are involved in the excessive induction of autophagy by propofol.

In further recent work, we showed in HEK RyR3-overexpression models, differentiated C2C12, cells and dissociated hippocampal neurons that spontaneous RyR activity inhibits basal autophagic flux (Vervliet et al., 2017). By blocking RyR activity with either dantrolene or an inhibitory dose of ryanodine, a reduction in LC3-II levels was observed. Including bafilomycin A1, a lysosomal degradation blocker, under these conditions increased LC3-II to similar levels as the control conditions. This suggested that the observed decrease in LC3-II levels upon RyR inhibition was due to an increased turnover of autophagosomes. Early markers of autophagy induction such as Beclin1, mTOR and AMPK activity were unaltered, confirming that inhibiting sporadic RyR-mediated $\mathrm{Ca}^{2+}$ release increases autophagic flux at the level of the lysosomes.

Although all three above studies reported a reduction in LC3-II levels upon RyR inhibition seemingly contradicting conclusions were drawn concerning the effects of RyR inhibition on autophagic flux. In the first two studies a decrease in autophagic flux was shown (Chung et al., 2016; Qiao et al., 2017), whereas the last study suggests a stimulation of autophagic flux upon RyR inhibition (Vervliet et al., 2017). A major difference between these studies is whether or not autophagy stimulating treatments or agents were used. The first two studies thus addressed the role of RyRs in autophagy induction by an external trigger, insulin deprivation or propofol treatment (Chung et al., 2016; Qiao et al., 2017). The third study focused on basal autophagy and spontaneous RyR activity (Vervliet et al., 2017). Although the conclusions of these studies appear seemingly contradictory, it is important to note that the role of $\mathrm{Ca}^{2+}$ signaling in basal vs. induced autophagy can be completely different and even opposite which has been illustrated for $\mathrm{IP}_{3} \mathrm{Rs}$ (Cárdenas et al., 2010; Decuypere et al., 2011b; Bootman et al., 2018).

Another recent study showed that RyR inhibition using dantrolene attenuated the observed alterations in autophagy in neurons from a mouse model for Gaucher disease (Liou et al., 2016). In this mouse model, neuronal RyR3 levels were reduced. In addition, an increase in LC3-II levels was observed compared to control mice. Treating these mice with dantrolene reduced the LC3-II levels compared to the untreated controls, improved mitochondrial function and overall survival rates. Strikingly, dantrolene treatment resulted in an increase in RyR3 levels to near WT levels. The authors concluded that dantrolene treatment could largely reverse the observed defects in autophagy in these mice, thereby normalizing basal autophagy.

In the heart RyR activity has been shown to regulate mitochondrial metabolism. Downregulation of RyR2 in cardiomyocytes resulted in decreased mitochondrial metabolism decreasing ATP production (Bround et al., 2013). Reduction of RyR2 triggered a hypoxia-like state thereby upregulating hypoxia inducible factor $(\mathrm{Hif} 1 \alpha)$, and presenilin-1 and -2 , and also increased autophagy induction. Reduced RyR2 levels lead to a calpain 10-dependent form of non-apoptotic programmed cell death, which has also been described to occur in pancreatic $\beta$-cells treated with RyR inhibitors (Dror et al., 2008). This study links RyR2-mediated $\mathrm{Ca}^{2+}$ release directly to mitochondrial metabolism, ATP production and the induction of autophagy. It is important to note that during ischemia reperfusion RyR2 levels in the heart drop dramatically due to calpain activity, proteasomal degradation and chaperone-mediated autophagy (Pedrozo et al., 2013). This was proposed to be protective as mitochondrial metabolism is slowed down, resulting in less production of reactive oxygen species. This study also showed that reducing RyR2 levels in cardiomyocytes triggers autophagy and may thus confer additional protection for cardiomyocytes. However, reduced RyR2 levels may impair cardiac contractility, which could lead to heart failure.

\section{RyR REGULATORS IN AUTOPHAGY}

\section{$\mathrm{Bcl}-2 / \mathrm{Bcl}-\mathrm{X}_{\mathrm{L}}$}

Anti-apoptotic $\mathrm{Bcl}-2$ proteins are known to inhibit autophagy by sequestering Beclin 1 thereby inhibiting its pro-autophagic actions (Pattingre et al., 2005). This interaction occurs via the hydrophobic cleft of the $\mathrm{Bcl}-2$ proteins and a $\mathrm{BH} 3$-like domain in Beclin 1 (Pedro et al., 2015). As Bcl-2 binds to Beclin 1 via its hydrophobic cleft and to the $\mathrm{IP}_{3} \mathrm{R}$ via its $\mathrm{BH} 4$ domain, it is possible that $\mathrm{Bcl}-2$ sequesters Beclin 1 at the $\mathrm{IP}_{3} \mathrm{R}$ (Decuypere et al., 2011a). When Beclin 1 is then released 
from $\mathrm{Bcl}-2$ it would be in close proximity of the $\mathrm{IP}_{3} \mathrm{R}$, where it may sensitize $\mathrm{IP}_{3} \mathrm{R}$-mediated $\mathrm{Ca}^{2+}$ release thereby promoting starvation-induced autophagy. At this point it is not known whether Bcl-2 bound to RyRs is associated with Beclin 1 and thus whether Beclin 1 can be found in a complex with RyRs. This is possible since Bcl-2 binding to the RyRs is independent of its hydrophobic cleft (Vervliet et al., 2015b). The hydrophobic cleft of $\mathrm{Bcl}-2$ proteins associated with RyRs might thus be available for other $\mathrm{BH} 3$-domain-containing proteins, like Beclin 1. It will be of interest to investigate whether Beclin 1 can bind to RyR channels directly or indirectly (e.g., via Bcl-2) and whether such complex formation impacts the function of the RyR in autophagy.

$\mathrm{Bcl}-2$ and $\mathrm{Bcl}-\mathrm{X}_{\mathrm{L}}$ both regulate $\mathrm{IP}_{3} \mathrm{R}$-mediated $\mathrm{Ca}^{2+}$ release (White et al., 2005; Rong et al., 2009; Decuypere et al., 2011a; Monaco et al., 2012) and mitochondrial $\mathrm{Ca}^{2+}$ uptake via VDAC (Shimizu et al., 1999, 2000; Arbel and ShoshanBarmatz, 2010). These proteins have a great impact on mitochondrial bioenergetics and ATP production and may also impact autophagy in this manner. As RyR-mediated $\mathrm{Ca}^{2+}$ release also regulates mitochondrial metabolism (Bround et al., 2013), inhibition of RyRs via Bcl-2 and Bcl- $\mathrm{X}_{\mathrm{L}}$ potentially also modulates autophagy through the regulation of RyR-mediated $\mathrm{Ca}^{2+}$ transfer to the mitochondria in certain cells. In addition, our data suggest that spontaneous RyR-mediated $\mathrm{Ca}^{2+}$ release inhibits the autophagic flux at the level of the lysosomes (Vervliet et al., 2017). As such, Bcl-2 and Bcl- $\mathrm{X}_{\mathrm{L}}$ could potentially promote autophagy by inhibiting basal RyR function.

\section{Presenilins}

In the heart, it was shown that downregulation of RyR2 induced a hypoxic-like condition associated with upregulation of presenilins (Bround et al., 2013). Similar observations were made in pancreatic $\beta$-cells where RyR inhibition resulted in depletion of ATP and a presenilin-dependent induction of Hifl $\alpha$ (Dror et al., 2008). This suggests a role for presenilins in regulating mitochondrial metabolism under stress conditions.

$\mathrm{AD}$-associated presenilin mutants have been shown to increase $\mathrm{IP}_{3} \mathrm{R}$-mediated $\mathrm{Ca}^{2+}$ release (Cheung et al., 2010). This may have direct effects on mitochondrial metabolism, energy production and autophagy (Bootman et al., 2018). RyR expression levels and functions are also regulated by presenilins (Payne et al., 2013; Wu et al., 2013). Knock down of presenilins for instance, reduced RyR expression levels in hippocampal neurons which in turn lowered RyR-mediated $\mathrm{Ca}^{2+}$ release in these neurons (Wu et al., 2013). This decrease in RyR signaling could potentially also regulate autophagic flux. However, at the moment it is not known whether presenilins regulate autophagy by targeting ER $\mathrm{Ca}^{2+}$ release channels.

\section{Polycystins}

PC1 and PC2 influence autophagy in a number of ways. First, they both control the activity of mTOR, an important kinase critically involved in autophagy induction (Laplante and Sabatini, 2012). Overexpression of PC1 resulted in decreased mTOR activity (Distefano et al., 2009) whereas either PC1 or PC2 knock-down increased mTOR activity (Rowe et al., 2013; Ravichandran et al., 2015; Orhon et al., 2016). In polycystic kidney disease, mTOR signaling is increased which correlates well with loss of function of PC1 and PC2 proteins (Shillingford et al., 2006).

In human embryonic stem cell-derived cardiomyocytes, PC2 was shown to regulate autophagy in a RyR2-dependent manner ( $\mathrm{Lu}$ et al., 2017). The authors showed that PC2 knockdown reduced autophagic flux after glucose deprivation. In contrast, PC2 overexpression was able to increase autophagic flux under the same conditions. Glucose deprivation was shown to increase the binding of PC2 with RyR2 which was necessary for maintaining increased RyR2-mediated $\mathrm{Ca}^{2+}$ release after glucose deprivation. Finally, it was shown that this PC2-RyR2-mediated $\mathrm{Ca}^{2+}$ signaling induced autophagy by increasing AMPK activity, thereby inhibiting mTOR signaling.

\section{THE RyR IN NEURODEGENERATIVE DISEASES}

Impaired or altered autophagic flux is a hallmark of several neurodegenerative diseases but also of aging. This is a novel topic in the field of autophagy and has recently been extensively reviewed (Kroemer, 2015; Fîlfan et al., 2017; Gao et al., 2017; Karabiyik et al., 2017; Liu et al., 2017; Moloudizargari et al., 2017; Guo et al., 2018; Wang et al., 2018). Dysregulated RyR expression/activity also play important roles in the development of a number of neurodegenerative diseases. These emerging roles for the RyR in several neurodegenerative diseases will be highlighted in this part of the review article.

\section{Alzheimer's Disease (AD)}

In the hippocampus of several $\mathrm{AD}$ mouse models, RyR3 levels were shown to be upregulated (Chan et al., 2000; Chakroborty et al., 2012; Oules et al., 2012). This results in excessive RyR-mediated $\mathrm{Ca}^{2+}$ release, which underlies early pathological events in $\mathrm{AD}$. Inhibition of RyRs using dantrolene reduced $\beta$ - and $\gamma$-secretase activity and the phosphorylation of the amyloid precursor protein thereby lowering amyloid beta plaque formation (Chakroborty et al., 2012; Oules et al., 2012). It must be noted that also negative effects of dantrolene-mediated RyR inhibition in $\mathrm{AD}$ have been reported (Chami and Checler, 2014; Liu et al., 2014). This discrepancy was explained by the time point at which these RyRs were inhibited. Using a RyR3 knockout mouse model in a triple transgenic AD mouse model background, it was shown that RyR3 activity may have a protective effect during the early stages of the disease. Inhibiting RyR3 at this point would thus promote disease progression. In contrast, in older mice, RyR3 appears to promote disease progression, suggesting that blocking the channel at this time may decelerate the development of AD. Recently, it was shown that post translational modifications of RyR2 occur in SH-SY5Y cells overexpressing an $\mathrm{AD}$ linked amyloid precursor protein mutation (Lacampagne et al., 2017). These modifications lead to leaky RyR2 channels thereby elevating basal cytosolic $\mathrm{Ca}^{2+}$ levels. Stabilizing this RyR2-mediated $\mathrm{Ca}^{2+}$ leak resulted in a decrease in the processing of the amyloid precursor protein to amyloid beta. Similar results were reported using AD mouse models in which stabilizing leaky RyR2 channels by enhancing the binding 
of FKBP12.6 to RyR2 reduced amyloid beta plaque formation and improved synaptic plasticity (Lacampagne et al., 2017).

\section{Huntington's Disease (HD)}

RyR activity was also shown to be important in the development of Huntington's disease (HD; Chen et al., 2011). Inhibition of RyRs by dantrolene in neurons obtained from a HD mouse model was shown to reduce glutamate-induced excitotoxicity. In addition, long term dantrolene feeding reduced the formation of pathological huntingtin aggregates and neuronal loss. Whether autophagy is also induced in these models after dantrolene treatment was not studied. It has been shown that compounds promoting autophagy by reducing $\mathrm{IP}_{3} \mathrm{R}$-mediated $\mathrm{Ca}^{2+}$ release, thereby inhibiting calpain activation, are beneficial for treating HD (Williams et al., 2008). As calpain activity is critically regulated by intracellular $\mathrm{Ca}^{2+}$, inhibition of RyRs could also reduce calpain activity and in turn activate autophagy. However, further research will be needed to elucidate whether or not RyRs are involved in calpain-mediated autophagy regulation.

\section{Parkinson's Disease}

Parkinson's disease is characterized by a loss of dopaminergic neurons, depletion of dopamine and mitochondrial dysfunction resulting in oxidative and excitotoxic stress (Hirsch et al., 2013). Recently, a new compound which showed neuroprotective effects in dopaminergic neurons, was tested in a Parkinson's disease mouse model (Le Douaron et al., 2016). The neuroprotective effects of this compound could be partially counteracted by dantrolene, suggesting this compound operates in part by activating RyR-mediated $\mathrm{Ca}^{2+}$ signaling. This is in agreement with previous studies where caffeine and paraxanthine, a metabolite of caffeine, were shown to promote dopaminergic neuron survival and increased dopamine secretion (Guerreiro et al., 2008; Xu et al., 2010). The neuro-protective effect of paraxanthine was attributed to a mild activation of the RyR. It may be important that RyRs were only mildly activated in order to not sensitize these neurons to excitotoxic cell death, as was illustrated in a Drosophila model of Parkinson's disease (Cassar et al., 2015). In this model, paraquat was used to induce oxidative stress, mimicking the disease. Reducing the amount of functional RyR channels in this model inhibited paraquatinduced cell death. Oxidative stress is a potent RyR sensitizer (Xu et al., 1998), which in turn could increase the sensitivity to excitotoxic stimuli. Reducing the amount of functional RyR channels may protect these cells from excitotoxic cell death.

\section{Spinocerebellar Ataxia}

Spinocerebellar ataxia (SCA) is a progressive neurodegenerative disease of which several types are known to exist (Sun et al., 2016). Activation of autophagy was shown to be beneficial in the treatment of certain forms of SCA (Nascimento-Ferreira et al., 2011). SCA type 2 and 3 are characterized by loss of Purkinje

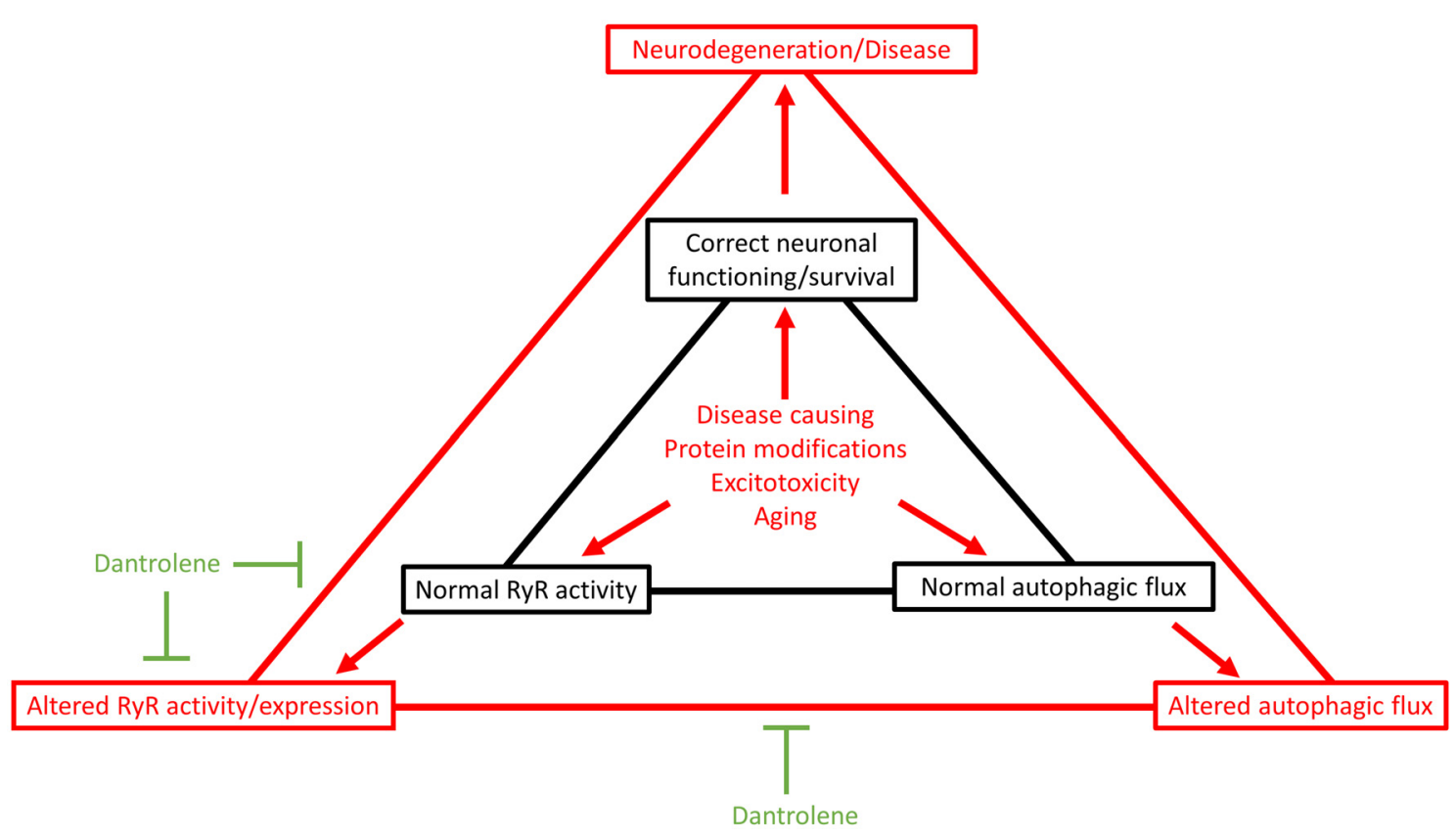

FIGURE 1 | The interplay between ryanodine receptors (RyRs) and autophagy contributes to neuronal function and health. Recent studies linked RyR signaling to autophagy suggest that RyR function and autophagy co-operate to maintain neuronal health (indicated in black). Disease causing mutant proteins, excitotoxicity and aging are known causes of neurodegenerative diseases. It is becoming increasingly clear that during the onset of these diseases changes in RyR signaling and autophagy occur contributing to the disease. These changes in RyR signaling may also affect the regulation of autophagy thereby accelerating even further the disease progression (indicated in red). Because of the link between RyR-mediated $\mathrm{Ca}^{2+}$ signaling and autophagy, the RyR inhibitor dantrolene could potentially via inhibiting RyRs also regulate autophagic flux. In this way, dantrolene may have multiple therapeutic effects (indicated in green). This may in part explain the beneficial effects of dantrolene treatment for several neurodegenerative diseases. 
cells due to aggregation of neurotoxic disease-causing mutant proteins. RyR activity is involved in the maturation of Purkinje cells (Ohashi et al., 2014). Increasing RyRs or RyR activity could potentially rescue the loss of Purkinje cells. This was explored in a SCA3 mouse model where increasing serotonin and RyR levels in the cerebellum rescued the loss of Purkinje cells associated with the disease (Hsieh et al., 2017). In a mouse model for SCA2 the mutant ataxin-2 protein was shown to trigger $\mathrm{IP}_{3} \mathrm{R}$-mediated $\mathrm{Ca}^{2+}$ release, which was amplified by RyR activity via CICR (Liu et al., 2009). Treatment of these mice with dantrolene protected Purkinje cells from excitotoxicity and cell death. These studies indicate that the RyR may be a potential target for treating certain types of SCA.

\section{CONCLUSION}

RyR signaling and autophagy are two factors critically linked to the correct functioning and survival of neurons (Figure 1, indicated in black). Studies showing how RyR-signaling regulates autophagy have only recently emerged making this a novel avenue in the autophagy field. In addition, several RyRinteracting/-modulating proteins have known roles in the regulation of autophagy which have not (yet) been linked to regulating RyR-mediated $\mathrm{Ca}^{2+}$ release. It will be interesting to see whether these interactors also influence autophagy by modulating RyR-mediated $\mathrm{Ca}^{2+}$ release.

Alterations in RyR-mediated $\mathrm{Ca}^{2+}$ release and autophagy have also been shown to contribute to several neurodegenerative diseases. Disease causing mutant proteins, excitotoxicity and aging are not only the cause for these diseases but also change RyR function and autophagy. As RyR function and autophagy are involved in maintaining neuronal health, changes

\section{REFERENCES}

Anyatonwu, G. I., Estrada, M., Tian, X., Somlo, S., and Ehrlich, B. E. (2007). Regulation of ryanodine receptor-dependent calcium signaling by polycystin-2. Proc. Natl. Acad. Sci. U S A 104, 6454-6459. doi: 10.1073/pnas.0610 324104

Arbel, N., and Shoshan-Barmatz, V. (2010). Voltage-dependent anion channel 1-based peptides interact with Bcl-2 to prevent antiapoptotic activity. J. Biol. Chem. 285, 6053-6062. doi: 10.1074/jbc.M109.082990

Bandara, S., Malmersjö, S., and Meyer, T. (2013). Regulators of calcium homeostasis identified by inference of kinetic model parameters from live single cells perturbed by siRNA. Sci. Signal. 6:ra56. doi: 10.1126/scisignal. 2003649

Berridge, M. J. (2001). The versatility and complexity of calcium signalling. Novartis Found. Symp. 239, 52-64; discussion 64-57, 150-159.

Berridge, M. J., Bootman, M. D., and Roderick, H. L. (2003). Calcium signalling: dynamics, homeostasis and remodelling. Nat. Rev. Mol. Cell Biol. 4, 517-529. doi: $10.1038 / \mathrm{nrm} 1155$

Bootman, M. D., Chehab, T., Bultynck, G., Parys, J. B., and Rietdorf, K. (2018). The regulation of autophagy by calcium signals: do we have a consensus? Cell Calcium 70, 32-46. doi: 10.1016/j.ceca.2017.08.005

Bround, M. J., Wambolt, R., Luciani, D. S., Kulpa, J. E., Rodrigues, B., Brownsey, R. W., et al. (2013). Cardiomyocyte ATP production, metabolic flexibility, and survival require calcium flux through cardiac ryanodine receptors in vivo. J. Biol. Chem. 288, 18975-18986. doi: 10.1074/jbc.M112. 427062

Brunelle, J. K., and Letai, A. (2009). Control of mitochondrial apoptosis by the Bcl-2 family. J. Cell Sci. 122, 437-441. doi: 10.1242/jcs.031682 in these processes may result in aggravating disease progression (Figure 1, indicated in red). Inhibition of RyR-mediated $\mathrm{Ca}^{2+}$ release has been shown to confer beneficial effects in treating a number of these diseases. Several of the above mentioned studies used the FDA-approved drug dantrolene in order to block RyR-mediated $\mathrm{Ca}^{2+}$ release. An observation common in the studies looking at how RyRs regulate autophagy, is that RyR inhibition via dantrolene changes/normalizes autophagic flux. This may in part underlie the beneficial effects of dantrolene in several neurodegenerative diseases as by inhibiting RyR activity it may also regulate autophagic flux indirectly (Figure 1, indicated in green). However, more research will be needed to gain further insights on the role of RyRs in regulating autophagy in the context of neurodegenerative diseases.

\section{AUTHOR CONTRIBUTIONS}

TV wrote this review article.

\section{FUNDING}

TV is a post-doctoral fellow funded by the Research FoundationFlanders (FWO). The research group in which TV is working is supported by grants from the Research Council-KU Leuven (BOF) and Research Foundation-Flanders (FWO).

\section{ACKNOWLEDGMENTS}

The author would like to thank Martijn Kerkhofs and Prof. Dr. Geert Bultynck for the interesting discussions and comments, which helped to shape this review article.

Bultynck, G. (2016). Onco- $\mathrm{IP}_{3}$ Rs feed cancerous cravings for mitochondrial $\mathrm{Ca}^{2+}$ Trends Biochem. Sci. 41, 390-393. doi: 10.1016/j.tibs.2016.03.006

Cárdenas, C., Müller, M., McNeal, A., Lovy, A., Jaňa, F., Bustos, G., et al. (2016). Selective vulnerability of cancer cells by inhibition of $\mathrm{Ca}^{2+}$ transfer from endoplasmic reticulum to mitochondria. Cell Rep. 15, 219-220. doi: 10.1016/j. celrep.2016.03.045

Cárdenas, C., Miller, R. A., Smith, I., Bui, T., Molgó, J., Müller, M., et al (2010). Essential regulation of cell bioenergetics by constitutive $\mathrm{InsP}_{3}$ receptor $\mathrm{Ca}^{2+}$ transfer to mitochondria. Cell 142, 270-283. doi: 10.1016/j.cell.2010. 06.007

Carreras-Sureda, A., Pihán, P., and Hetz, C. (2018). Calcium signaling at the endoplasmic reticulum: fine-tuning stress responses. Cell Calcium 70, 24-31. doi: 10.1016/j.ceca.2017.08.004

Cassar, M., Issa, A. R., Riemensperger, T., Petitgas, C., Rival, T., Coulom, H., et al. (2015). A dopamine receptor contributes to paraquat-induced neurotoxicity in Drosophila. Hum. Mol. Genet. 24, 197-212. doi: 10.1093/hmg/ ddu430

Chakroborty, S., Briggs, C., Miller, M. B., Goussakov, I., Schneider, C., Kim, J., et al. (2012). Stabilizing ER $\mathrm{Ca}^{2+}$ channel function as an early preventative strategy for Alzheimer's disease. PLoS One 7:e52056. doi: 10.1371/journal.pone.0052056

Chami, M., and Checler, F. (2014). Ryanodine receptors: dual contribution to Alzheimer disease? Channels 8:168. doi: 10.4161/chan.29000

Chan, S. L., Mayne, M., Holden, C. P., Geiger, J. D., and Mattson, M. P. (2000). Presenilin-1 mutations increase levels of ryanodine receptors and calcium release in PC12 cells and cortical neurons. J. Biol. Chem. 275, 18195-18200. doi: 10.1074/jbc.M000040200

Chen, R., Valencia, I., Zhong, F., McColl, K. S., Roderick, H. L., Bootman, M. D., et al. (2004). Bcl-2 functionally interacts with inositol 1,4,5-trisphosphate 
receptors to regulate calcium release from the ER in response to inositol 1,4,5trisphosphate. J. Cell Biol. 166, 193-203. doi: 10.1083/jcb.200309146

Chen, X., Wu, J., Lvovskaya, S., Herndon, E., Supnet, C., and Bezprozvanny, I. (2011). Dantrolene is neuroprotective in Huntington's disease transgenic mouse model. Mol. Neurodegener. 6:81. doi: 10.1186/1750-1326-6-81

Cheung, K. H., Mei, L., Mak, D. O., Hayashi, I., Iwatsubo, T., Kang, D. E., et al. (2010). Gain-of-function enhancement of $\mathrm{IP}_{3}$ receptor modal gating by familial Alzheimer's disease-linked presenilin mutants in human cells and mouse neurons. Sci. Signal. 3:ra22. doi: 10.1126/scisignal.2000818

Chung, K. M., Jeong, E. J., Park, H., An, H. K., and Yu, S. W. (2016). Mediation of autophagic cell death by type 3 ryanodine receptor (RyR3) in adult hippocampal neural stem cells. Front. Cell. Neurosci. 10:116. doi: 10.3389/fncel. 2016.00116

De Strooper, B., Iwatsubo, T., and Wolfe, M. S. (2012). Presenilins and $\gamma$-secretase: structure, function, and role in Alzheimer disease. Cold Spring Harb. Perspect. Med. 2:a006304. doi: 10.1101/cshperspect.a006304

Decuypere, J. P., Bultynck, G., and Parys, J. B. (2011a). A dual role for $\mathrm{Ca}^{2+}$ in autophagy regulation. Cell Calcium 50, 242-250. doi: 10.1016/j.ceca.2011. 04.001

Decuypere, J. P., Welkenhuyzen, K., Luyten, T., Ponsaerts, R., Dewaele, M., Molgo, J., et al. (2011b). Ins(1,4,5)P3 receptor-mediated $\mathrm{Ca}^{2+}$ signaling and autophagy induction are interrelated. Autophagy 7, 1472-1489. doi: 10.4161/auto.7.12.17909

Delling, M., DeCaen, P. G., Doerner, J. F., Febvay, S., and Clapham, D. E. (2013). Primary cilia are specialized calcium signalling organelles. Nature 504, 311-314. doi: 10.1038/nature12833

Distefano, G., Boca, M., Rowe, I., Wodarczyk, C., Ma, L., Piontek, K. B., et al. (2009). Polycystin-1 regulates extracellular signal-regulated kinasedependent phosphorylation of tuberin to control cell size through mTOR and its downstream effectors S6K and 4EBP1. Mol. Cell. Biol. 29, 2359-2371. doi: 10.1128/MCB.01259-08

Dremina, E. S., Sharov, V. S., Kumar, K., Zaidi, A., Michaelis, E. K., and Schoneich, C. (2004). Anti-apoptotic protein Bcl-2 interacts with and destabilizes the sarcoplasmic/endoplasmic reticulum $\mathrm{Ca}^{2+}$-ATPase (SERCA). Biochem. J. 383, 361-370. doi: 10.1042/BJ20040187

Dror, V., Kalynyak, T. B., Bychkivska, Y., Frey, M. H., Tee, M., Jeffrey, K. D., et al. (2008). Glucose and endoplasmic reticulum calcium channels regulate HIF-1 $\beta$ via presenilin in pancreatic $\beta$-cells. J. Biol. Chem. 283, 9909-9916. doi: 10.1074/jbc.M710601200

Eckenrode, E. F., Yang, J., Velmurugan, G. V., Foskett, J. K., and White, C. (2010). Apoptosis protection by Mcl-1 and Bcl-2 modulation of inositol 1,4,5-trisphosphate receptor-dependent $\mathrm{Ca}^{2+}$ signaling. J. Biol. Chem. 285, 13678-13684. doi: 10.1074/jbc.M109.096040

Edinger, A. L., and Thompson, C. B. (2004). Death by design: apoptosis, necrosis and autophagy. Curr. Opin. Cell Biol. 16, 663-669. doi: 10.1016/j.ceb.2004. 09.011

Ferdek, P. E., Gerasimenko, J. V., Peng, S., Tepikin, A. V., Petersen, O. H., and Gerasimenko, O. V. (2012). A novel role for Bcl-2 in regulation of cellular calcium extrusion. Curr. Biol. 22, 1241-1246. doi: 10.1016/j.cub.2012. 05.002

Fîlfan, M., Sandu, R. E., Zăvăleanu, A. D., GreşiTă, A., Glăvan, D. G., Olaru, D. G., et al. (2017). Autophagy in aging and disease. Rom. J. Morphol. Embryol. 58, $27-31$.

Foskett, J. K., White, C., Cheung, K. H., and Mak, D. O. (2007). Inositol trisphosphate receptor $\mathrm{Ca}^{2+}$ release channels. Physiol. Rev. 87, 593-658. doi: 10.1152/physrev.00035.2006

Gao, F., Yang, J., Wang, D., Li, C., Fu, Y., Wang, H., et al. (2017). Mitophagy in Parkinson's disease: pathogenic and therapeutic implications. Front. Neurol. 8:527. doi: 10.3389/fneur.2017.00527

Gerasimenko, J. V., Sherwood, M., Tepikin, A. V., Petersen, O. H., and Gerasimenko, O. V. (2006). NAADP, cADPR and $\mathrm{IP}_{3}$ all release $\mathrm{Ca}^{2+}$ from the endoplasmic reticulum and an acidic store in the secretory granule area. J. Cell Sci. 119, 226-238. doi: 10.1242/jcs.02721

Guerreiro, S., Toulorge, D., Hirsch, E., Marien, M., Sokoloff, P., and Michel, P. P. (2008). Paraxanthine, the primary metabolite of caffeine, provides protection against dopaminergic cell death via stimulation of ryanodine receptor channels. Mol. Pharmacol. 74, 980-989. doi: 10.1124/mol.108. 048207
Guo, F., Liu, X., Cai, H., and Le, W. (2018). Autophagy in neurodegenerative diseases: pathogenesis and therapy. Brain Pathol. 28, 3-13. doi: 10.1111/bpa. 12545

Hanson, C. J., Bootman, M. D., Distelhorst, C. W., Wojcikiewicz, R. J., and Roderick, H. L. (2008). Bcl-2 suppresses $\mathrm{Ca}^{2+}$ release through inositol 1,4,5trisphosphate receptors and inhibits $\mathrm{Ca}^{2+}$ uptake by mitochondria without affecting ER calcium store content. Cell Calcium 44, 324-338. doi: 10.1016/j. ceca.2008.01.003

Hirsch, E. C., Jenner, P., and Przedborski, S. (2013). Pathogenesis of Parkinson's disease. Mov. Disord. 28, 24-30. doi: 10.1002/mds.25032

Høyer-Hansen, M., Bastholm, L., Szyniarowski, P., Campanella, M., Szabadkai, G., Farkas, T., et al. (2007). Control of macroautophagy by calcium, calmodulindependent kinase kinase- $\beta$, and Bcl-2. Mol. Cell 25, 193-205. doi: 10.1016/j. molcel.2006.12.009

Hsieh, J., Liu, J. W., Harn, H. J., Hsueh, K. W., Rajamani, K., Deng, Y. C., et al. (2017). Human olfactory ensheathing cell transplantation improves motor function in a mouse model of type 3 spinocerebellar ataxia. Cell Transplant. 26, 1611-1621. doi: 10.1177/0963689717732578

Husain, S. Z., Orabi, A. I., Muili, K. A., Luo, Y., Sarwar, S., Mahmood, S. M., et al. (2012). Ryanodine receptors contribute to bile acid-induced pathological calcium signaling and pancreatitis in mice. Am. J. Physiol. Gastrointest. Liver Physiol. 302, G1423-G1433. doi: 10.1152/ajpgi.00546.2011

Imagawa, T., Takasago, T., and Shigekawa, M. (1989). Cardiac ryanodine receptor is absent in type I slow skeletal muscle fibers: immunochemical and ryanodine binding studies. J. Biochem. 106, 342-348. doi: 10.1093/oxfordjournals.jbchem. a122855

Ivanova, H., Vervliet, T., Missiaen, L., Parys, J. B., De Smedt, H., and Bultynck, G. (2014). Inositol 1,4,5-trisphosphate receptor-isoform diversity in cell death and survival. Biochim. Biophys. Acta 1843, 2164-2183. doi: 10.1016/j.bbamcr.2014. 03.007

Kania, E., Roest, G., Vervliet, T., Parys, J. B., and Bultynck, G. (2017). IP 3 receptormediated calcium signaling and its role in autophagy in cancer. Front. Oncol. 7:140. doi: $10.3389 /$ fonc.2017.00140

Karabiyik, C., Lee, M. J., and Rubinsztein, D. C. (2017). Autophagy impairment in Parkinson's disease. Essays Biochem. 61, 711-720. doi: 10.1042/EBC20170023

Karen, T., Schlager, G. W., Bendix, I., Sifringer, M., Herrmann, R., Pantazis, C., et al. (2013). Effect of propofol in the immature rat brain on shortand long-term neurodevelopmental outcome. PLoS One 8:e64480. doi: 10.1371 /journal.pone.0064480

Kasri, N. N., Kocks, S. L., Verbert, L., Hébert, S. S., Callewaert, G., Parys, J. B., et al. (2006). Up-regulation of inositol 1,4,5-trisphosphate receptor type 1 is responsible for a decreased endoplasmic-reticulum $\mathrm{Ca}^{2+}$ content in presenilin double knock-out cells. Cell Calcium 40, 41-51. doi: 10.1016/j.ceca.2006.03.005

Kilpatrick, B. S., Eden, E. R., Hockey, L. N., Yates, E., Futter, C. E., and Patel, S. (2017). An endosomal NAADP-sensitive two-pore $\mathrm{Ca}^{2+}$ channel regulates ER-endosome membrane contact sites to control growth factor signaling. Cell Rep. 18, 1636-1645. doi: 10.1016/j.celrep.2017.01.052

Klionsky, D. J., Abdelmohsen, K., Abe, A., Abedin, M. J., Abeliovich, H., Acevedo Arozena, A., et al. (2016). Guidelines for the use and interpretation of assays for monitoring autophagy (3rd edition). Autophagy 12, 1-222. doi: 10.1080/15548627.2015.1100356

Kroemer, G. (2015). Autophagy: a druggable process that is deregulated in aging and human disease. J. Clin. Invest. 125, 1-4. doi: 10.1172/jci78652

Kunerth, S., Langhorst, M. F., Schwarzmann, N., Gu, X., Huang, L., Yang, Z., et al. (2004). Amplification and propagation of pacemaker $\mathrm{Ca}^{2+}$ signals by cyclic ADP-ribose and the type 3 ryanodine receptor in T cells. J. Cell Sci. 117, 2141-2149. doi: $10.1242 /$ jcs. 01063

Kuo, I. Y., Kwaczala, A. T., Nguyen, L., Russell, K. S., Campbell, S. G., and Ehrlich, B. E. (2014). Decreased polycystin 2 expression alters calciumcontraction coupling and changes $\beta$-adrenergic signaling pathways. Proc. Natl. Acad. Sci. U S A 111, 16604-16609. doi: 10.1073/pnas.1415933111

La Rovere, R. M., Roest, G., Bultynck, G., and Parys, J. B. (2016). Intracellular Ca ${ }^{2+}$ signaling and $\mathrm{Ca}^{2+}$ microdomains in the control of cell survival, apoptosis and autophagy. Cell Calcium 60, 74-87. doi: 10.1016/j.ceca.2016.04.005

Lacampagne, A., Liu, X., Reiken, S., Bussiere, R., Meli, A. C., Lauritzen, I., et al. (2017). Post-translational remodeling of ryanodine receptor induces calcium leak leading to Alzheimer's disease-like pathologies and cognitive deficits. Acta Neuropathol. 134, 749-767. doi: 10.1007/s00401-017-1733-7 
Lai, F. A., and Meissner, G. (1989). The muscle ryanodine receptor and its intrinsic $\mathrm{Ca}^{2+}$ channel activity. J. Bioenerg. Biomembr. 21, 227-246. doi: $10.1007 / \mathrm{bf} 00812070$

Lanner, J. T., Georgiou, D. K., Joshi, A. D., and Hamilton, S. L. (2010). Ryanodine receptors: structure, expression, molecular details, and function in calcium release. Cold Spring Harb. Perspect. Biol. 2:a003996. doi: 10.1101/cshperspect. a003996

Laplante, M., and Sabatini, D. M. (2012). mTOR signaling in growth control and disease. Cell 149, 274-293. doi: 10.1016/j.cell.2012.03.017

Laude, A. J., and Simpson, A. W. (2009). Compartmentalized signalling: $\mathrm{Ca}^{2+}$ compartments, microdomains and the many facets of $\mathrm{Ca}^{2+}$ signalling. FEBS J. 276, 1800-1816. doi: 10.1111/j.1742-4658.2009.06927.x

Law, B. Y., Wang, M., Ma, D. L., Al-Mousa, F., Michelangeli, F., Cheng, S. H., et al. (2010). Alisol B, a novel inhibitor of the sarcoplasmic/endoplasmic reticulum $\mathrm{Ca}^{2+}$ ATPase pump, induces autophagy, endoplasmic reticulum stress, and apoptosis. Mol. Cancer Ther. 9, 718-730. doi: 10.1158/1535-7163. MCT-09-0700

Le Douaron, G., Ferrié, L., Sepulveda-Diaz, J. E., Amar, M., Harfouche, A., Séon-Méniel, B., et al. (2016). New 6-aminoquinoxaline derivatives with neuroprotective effect on dopaminergic neurons in cellular and animal parkinson disease models. J. Med. Chem. 59, 6169-6186. doi: 10.1021/acs. jmedchem.6b00297

Lemos, F. O., and Ehrlich, B. E. (2018). Polycystin and calcium signaling in cell death and survival. Cell Calcium 69, 37-45. doi: 10.1016/j.ceca.2017.05.011

Letai, A. G. (2008). Diagnosing and exploiting cancer's addiction to blocks in apoptosis. Nat. Rev. Cancer 8, 121-132. doi: 10.1038/nrc2297

Li, Y., Santoso, N. G., Yu, S., Woodward, O. M., Qian, F., and Guggino, W. B. (2009). Polycystin-1 interacts with inositol 1,4,5-trisphosphate receptor to modulate intracellular $\mathrm{Ca}^{2+}$ signaling with implications for polycystic kidney disease. J. Biol. Chem. 284, 36431-36441. doi: 10.1074/jbc.M109. 068916

Li, Y., Wright, J. M., Qian, F., Germino, G. G., and Guggino, W. B. (2005). Polycystin 2 interacts with type I inositol 1,4,5-trisphosphate receptor to modulate intracellular $\mathrm{Ca}^{2+}$ signaling. J. Biol. Chem. 280, 41298-41306. doi: 10.1074/jbc.M510082200

Liou, B., Peng, Y., Li, R., Inskeep, V., Zhang, W., Quinn, B., et al. (2016). Modulating ryanodine receptors with dantrolene attenuates neuronopathic phenotype in Gaucher disease mice. Hum. Mol. Genet. 25, 5126-5141. doi: $10.1093 / \mathrm{hmg} / \mathrm{ddw} 322$

Liu, H., Dai, C., Fan, Y., Guo, B., Ren, K., Sun, T., et al. (2017). From autophagy to mitophagy: the roles of P62 in neurodegenerative diseases. J. Bioenerg. Biomembr. 49, 413-422. doi: 10.1007/s10863-017-9727-7

Liu, J., Supnet, C., Sun, S., Zhang, H., Good, L., Popugaeva, E., et al. (2014). The role of ryanodine receptor type 3 in a mouse model of Alzheimer disease. Channels 8, 230-242. doi: 10.4161/chan.27471

Liu, J., Tang, T. S., Tu, H., Nelson, O., Herndon, E., Huynh, D. P., et al. (2009). Deranged calcium signaling and neurodegeneration in spinocerebellar ataxia type 2. J. Neurosci. 29, 9148-9162. doi: 10.1523/JNEUROSCI.0660-09.2009

Lu, J., Boheler, K. R., Jiang, L., Chan, C. W., Tse, W. W., Keung, W., et al. (2017). Polycystin-2 plays an essential role in glucose starvation-induced autophagy in human embryonic stem cell-derived cardiomyocytes. Stem Cells doi: 10.1002/stem.2764 [Epub ahead of print].

Martin, C., Chapman, K. E., Seckl, J. R., and Ashley, R. H. (1998). Partial cloning and differential expression of ryanodine receptor calcium-release channel genes in human tissues including the hippocampus and cerebellum. Neuroscience 85, 205-216. doi: 10.1016/s0306-4522(97)00612-x

Meissner, G., Rios, E., Tripathy, A., and Pasek, D. A. (1997). Regulation of skeletal muscle $\mathrm{Ca}^{2+}$ release channel (ryanodine receptor) by $\mathrm{Ca}^{2+}$ and monovalent cations and anions. J. Biol. Chem. 272, 1628-1638. doi: 10.1074/jbc.272.3.1628

Mekahli, D., Bultynck, G., Parys, J. B., De Smedt, H., and Missiaen, L. (2011). Endoplasmic-reticulum calcium depletion and disease. Cold Spring Harb. Perspect. Biol. 3:a004317. doi: 10.1101/cshperspect.a004317

Mikoshiba, K. (2015). Role of $\mathrm{IP}_{3}$ receptor signaling in cell functions and diseases. Adv. Biol. Regul. 57, 217-227. doi: 10.1016/j.jbior.2014.10.001

Milanovic, D., Popic, J., Pesic, V., Loncarevic-Vasiljkovic, N., Kanazir, S., JevtovicTodorovic, V., et al. (2010). Regional and temporal profiles of calpain and caspase-3 activities in postnatal rat brain following repeated propofol administration. Dev. Neurosci. 32, 288-301. doi: 10.1159/000316970
Moloudizargari, M., Asghari, M. H., Ghobadi, E., Fallah, M., Rasouli, S., and Abdollahi, M. (2017). Autophagy, its mechanisms and regulation: implications in neurodegenerative diseases. Ageing Res. Rev. 40, 64-74. doi: 10.1016/j.arr. 2017.09.005

Monaco, G., Decrock, E., Akl, H., Ponsaerts, R., Vervliet, T., Luyten, T., et al. (2012). Selective regulation of $\mathrm{IP}_{3}$-receptor-mediated $\mathrm{Ca}^{2+}$ signaling and apoptosis by the $\mathrm{BH} 4$ domain of $\mathrm{Bcl}-2$ versus $\mathrm{Bcl}-\mathrm{X}_{\mathrm{L}}$. Cell Death Differ. 19, 295-309. doi: 10.1038/cdd.2011.97

Nascimento-Ferreira, I., Santos-Ferreira, T., Sousa-Ferreira, L., Auregan, G., Onofre, I., Alves, S., et al. (2011). Overexpression of the autophagic beclin-1 protein clears mutant ataxin-3 and alleviates Machado-Joseph disease. Brain 134, 1400-1415. doi: 10.1093/brain/awr047

Nelson, O., Tu, H., Lei, T., Bentahir, M., de Strooper, B., and Bezprozvanny, I. (2007). Familial Alzheimer disease-linked mutations specifically disrupt $\mathrm{Ca}^{2+}$ leak function of presenilin 1. J. Clin. Invest. 117, 1230-1239. doi: 10.1172/JCI30447

Ohashi, R., Sakata, S., Naito, A., Hirashima, N., and Tanaka, M. (2014). Dendritic differentiation of cerebellar Purkinje cells is promoted by ryanodine receptors expressed by Purkinje and granule cells. Dev. Neurobiol. 74, 467-480. doi: 10.1002/dneu.22139

Orhon, I., Dupont, N., Zaidan, M., Boitez, V., Burtin, M., Schmitt, A., et al. (2016). Primary-cilium-dependent autophagy controls epithelial cell volume in response to fluid flow. Nat. Cell Biol. 18, 657-667. doi: 10.1038/ncb3360

Oules, B., Del Prete, D., Greco, B., Zhang, X., Lauritzen, I., Sevalle, J., et al. (2012). Ryanodine receptor blockade reduces amyloid- $\beta$ load and memory impairments in Tg2576 mouse model of Alzheimer disease. J. Neurosci. 32, 11820-11834. doi: 10.1523/JNEUROSCI.0875-12.2012

Parys, J. B., Decuypere, J. P., and Bultynck, G. (2012). Role of the inositol 1,4,5trisphosphate receptor/ $\mathrm{Ca}^{2+}$-release channel in autophagy. Cell Commun. Signal. 10:17. doi: 10.1186/1478-811X-10-17

Parys, J. B., and De Smedt, H. (2012). Inositol 1,4,5-trisphosphate and its receptors. Adv. Exp. Med. Biol. 740, 255-279. doi: 10.1007/978-94-007-2888-2_11

Pattingre, S., Tassa, A., Qu, X., Garuti, R., Liang, X. H., Mizushima, N., et al. (2005). Bcl-2 antiapoptotic proteins inhibit Beclin 1-dependent autophagy. Cell 122, 927-939. doi: 10.1016/j.cell.2005.07.002

Payne, A. J., Gerdes, B. C., Naumchuk, Y., McCalley, A. E., Kaja, S., and Koulen, P. (2013). Presenilins regulate the cellular activity of ryanodine receptors differentially through isotype-specific $\mathrm{N}$-terminal cysteines. Exp. Neurol. 250, 143-150. doi: 10.1016/j.expneurol.2013.09.001

Pedriali, G., Rimessi, A., Sbano, L., Giorgi, C., Wieckowski, M. R., Previati, M., et al. (2017). Regulation of endoplasmic reticulum-mitochondria $\mathrm{Ca}^{2+}$ transfer and its importance for anti-cancer therapies. Front. Oncol. 7:180. doi: 10.3389/fonc. 2017.00180

Pedro, J. M., Wei, Y., Sica, V., Maiuri, M. C., Zou, Z., Kroemer, G., et al. (2015). BAX and BAK1 are dispensable for ABT-737-induced dissociation of the BCL2-BECN1 complex and autophagy. Autophagy 11, 452-459. doi: 10.1080/15548627.2015.1017191

Pedrozo, Z., Torrealba, N., Fernñndez, C., Gatica, D., Toro, B., Quiroga, C., et al. (2013). Cardiomyocyte ryanodine receptor degradation by chaperonemediated autophagy. Cardiovasc. Res. 98, 277-285. doi: 10.1093/cvr/ cvt029

Qiao, H., Li, Y., Xu, Z., Li, W., Fu, Z., Wang, Y., et al. (2017). Propofol affects neurodegeneration and neurogenesis by regulation of autophagy via effects on intracellular calcium homeostasis. Anesthesiology 127, 490-501. doi: 10.1097/ALN.0000000000001730

Raffaello, A., Mammucari, C., Gherardi, G., and Rizzuto, R. (2016). Calcium at the center of cell signaling: interplay between endoplasmic reticulum, mitochondria, and lysosomes. Trends Biochem. Sci. 41, 1035-1049. doi: 10.1016/j.tibs.2016.09.001

Ravichandran, K., Zafar, I., Ozkok, A., and Edelstein, C. L. (2015). An mTOR kinase inhibitor slows disease progression in a rat model of polycystic kidney disease. Nephrol. Dial. Transplant. 30, 45-53. doi: 10.1093/ndt/ gfu296

Rong, Y. P., Bultynck, G., Aromolaran, A. S., Zhong, F., Parys, J. B., De Smedt, H., et al. (2009). The BH4 domain of Bcl-2 inhibits ER calcium release and apoptosis by binding the regulatory and coupling domain of the IP3 receptor. Proc. Natl. Acad. Sci. U S A 106, 14397-14402. doi: 10.1073/pnas.0907 555106 
Rowe, I., Chiaravalli, M., Mannella, V., Ulisse, V., Quilici, G., Pema, M., et al. (2013). Defective glucose metabolism in polycystic kidney disease identifies a new therapeutic strategy. Nat. Med. 19, 488-493. doi: 10.1038/nm.3092

Sammels, E., Devogelaere, B., Mekahli, D., Bultynck, G., Missiaen, L., Parys, J. B., et al. (2010a). Polycystin-2 activation by inositol 1,4,5-trisphosphate-induced $\mathrm{Ca}^{2+}$ release requires its direct association with the inositol 1,4,5-trisphosphate receptor in a signaling microdomain. J. Biol. Chem. 285, 18794-18805. doi: 10.1074/jbc.M109.090662

Sammels, E., Parys, J. B., Missiaen, L., De Smedt, H., and Bultynck, G. (2010b). Intracellular $\mathrm{Ca}^{2+}$ storage in health and disease: a dynamic equilibrium. Cell Calcium 47, 297-314. doi: 10.1016/j.ceca.2010.02.001

Santulli, G., Pagano, G., Sardu, C., Xie, W., Reiken, S., D’Ascia, S. L., et al. (2015). Calcium release channel RyR2 regulates insulin release and glucose homeostasis. J. Clin. Invest. 125, 1968-1978. doi: 10.1172/JCI79273

Selkoe, D. J., and Hardy, J. (2016). The amyloid hypothesis of Alzheimer's disease at 25 years. EMBO Mol. Med. 8, 595-608. doi: 10.15252/emmm. 201606210

Shillingford, J. M., Murcia, N. S., Larson, C. H., Low, S. H., Hedgepeth, R., Brown, N., et al. (2006). The mTOR pathway is regulated by polycystin-1 and its inhibition reverses renal cystogenesis in polycystic kidney disease. Proc. Natl. Acad. Sci. U S A 103, 5466-5471. doi: 10.1073/pnas.0509694103

Shimizu, S., Konishi, A., Kodama, T., and Tsujimoto, Y. (2000). BH4 domain of antiapoptotic Bcl-2 family members closes voltage-dependent anion channel and inhibits apoptotic mitochondrial changes and cell death. Proc. Natl. Acad. Sci. U S A 97, 3100-3105. doi: 10.1073/pnas.97.7.3100

Shimizu, S., Narita, M., and Tsujimoto, Y. (1999). Bcl-2 family proteins regulate the release of apoptogenic cytochrome $\mathrm{c}$ by the mitochondrial channel VDAC. Nature 399, 483-487. doi: 10.1038/20959

Sun, Y. M., Lu, C., and Wu, Z. Y. (2016). Spinocerebellar ataxia: relationship between phenotype and genotype-a review. Clin. Genet. 90, 305-314. doi: $10.1111 /$ cge. 12808

Thul, R., Bellamy, T. C., Roderick, H. L., Bootman, M. D., and Coombes, S. (2008). Calcium oscillations. Adv. Exp. Med. Biol. 641, 1-27. doi: 10.1007/978-0-38709794-7_1

Torres, V. E., Harris, P. C., and Pirson, Y. (2007). Autosomal dominant polycystic kidney disease. Lancet 369, 1287-1301. doi: 10.1016/S0140-6736(07)60601-1

Tsiokas, L., Kim, S., and Ong, E. C. (2007). Cell biology of polycystin-2. Cell. Signal. 19, 444-453. doi: 10.1016/j.cellsig.2006.09.005

Vandecaetsbeek, I., Vangheluwe, P., Raeymaekers, L., Wuytack, F., and Vanoevelen, J. (2011). The $\mathrm{Ca}^{2+}$ pumps of the endoplasmic reticulum and Golgi apparatus. Cold Spring Harb. Perspect. Biol. 3:a004184. doi: 10.1101/cshperspect.a004184

Vervliet, T., Decrock, E., Molgó, J., Sorrentino, V., Missiaen, L., Leybaert, L., et al. (2014). Bcl-2 binds to and inhibits ryanodine receptors. J. Cell Sci. 127, 2782-2792. doi: 10.1242/jcs.150011

Vervliet, T., Lemmens, I., Vandermarliere, E., Decrock, E., Ivanova, H., Monaco, G., et al. (2015a). Ryanodine receptors are targeted by anti-apoptotic Bcl-XL involving its BH4 domain and Lys87 from its BH3 domain. Sci. Rep. 5:9641. doi: 10.1038/srep09641
Vervliet, T., Lemmens, I., Welkenhuyzen, K., Tavernier, J., Parys, J. B., and Bultynck, G. (2015b). Regulation of the ryanodine receptor by anti-apoptotic $\mathrm{Bcl}-2$ is independent of its $\mathrm{BH} 3$-domain-binding properties. Biochem. Biophys. Res. Commun. 463, 174-179. doi: 10.1016/j.bbrc.2015.04.131

Vervliet, T., Parys, J. B., and Bultynck, G. (2016). Bcl-2 proteins and calcium signaling: complexity beneath the surface. Oncogene 35, 5079-5092. doi: 10.1038 /onc. 2016.31

Vervliet, T., Pintelon, I., Welkenhuyzen, K., Bootman, M. D., Bannai, H., Mikoshiba, K., et al. (2017). Basal ryanodine receptor activity suppresses autophagic flux. Biochem. Pharmacol. 132, 133-142. doi: 10.1016/j.bcp.2017. 03.011

Wang, C., Telpoukhovskaia, M. A., Bahr, B. A., Chen, X., and Gan, L. (2018). Endo-lysosomal dysfunction: a converging mechanism in neurodegenerative diseases. Curr. Opin. Neurobiol. 48, 52-58. doi: 10.1016/j.conb.2017.09.005

White, C., Li, C., Yang, J., Petrenko, N. B., Madesh, M., Thompson, C. B., et al. (2005). The endoplasmic reticulum gateway to apoptosis by $\mathrm{Bcl}-\mathrm{X}_{\mathrm{L}}$ modulation of the InsP ${ }_{3}$ R. Nat. Cell Biol. 7, 1021-1028. doi: 10.1038/ncb1302

Williams, A., Sarkar, S., Cuddon, P., Ttofi, E. K., Saiki, S., Siddiqi, F. H., et al. (2008). Novel targets for Huntington's disease in an mTOR-independent autophagy pathway. Nat. Chem. Biol. 4, 295-305. doi: 10.1038/nchembio.79

Wu, B., Yamaguchi, H., Lai, F. A., and Shen, J. (2013). Presenilins regulate calcium homeostasis and presynaptic function via ryanodine receptors in hippocampal neurons. Proc. Natl. Acad. Sci. U S A 110, 15091-15096. doi: 10.1073/pnas. 1304171110

Xia, H. G., Zhang, L., Chen, G., Zhang, T., Liu, J., Jin, M., et al. (2010). Control of basal autophagy by calpain 1 mediated cleavage of ATG5. Autophagy 6, 61-66. doi: 10.4161/auto.6.1.10326

Xu, L., Eu, J. P., Meissner, G., and Stamler, J. S. (1998). Activation of the cardiac calcium release channel (ryanodine receptor) by poly-S-nitrosylation. Science 279, 234-237. doi: 10.1126/science.279.5348.234

Xu, K., Xu, Y. H., Chen, J. F., and Schwarzschild, M. A. (2010). Neuroprotection by caffeine: time course and role of its metabolites in the MPTP model of Parkinson's disease. Neuroscience 167, 475-481. doi: 10.1016/j.neuroscience. 2010.02.020

Yang, J., Vais, H., Gu, W., and Foskett, J. K. (2016). Biphasic regulation of InsP3 receptor gating by dual $\mathrm{Ca}^{2+}$ release channel $\mathrm{BH} 3$-like domains mediates Bcl-xL control of cell viability. Proc. Natl. Acad. Sci. U S A 113, E1953-E1962. doi: 10.1073/pnas.1517935113

Conflict of Interest Statement: The author declares that the research was conducted in the absence of any commercial or financial relationships that could be construed as a potential conflict of interest.

Copyright (C) 2018 Vervliet. This is an open-access article distributed under the terms of the Creative Commons Attribution License (CC BY). The use, distribution or reproduction in other forums is permitted, provided the original author(s) and the copyright owner are credited and that the original publication in this journal is cited, in accordance with accepted academic practice. No use, distribution or reproduction is permitted which does not comply with these terms. 